Jurnal Akuntansi \& Perpajakan, Volume 2, No. 1, Juli 2020

\title{
TAXPAYER PERCEPTION RELATED TO LOVE OF MONEY, MACHIAVELLIAN, AND EQUITY SENSITIVITY ON TAX EVASION ETHICS
}

\author{
Esther Dwitia $^{1}$, Masripah ${ }^{2}$, Ni Putu Eka Widiastuti³ \\ 1,2,3 Universitas Pembangunan Nasional Veteran Jakarta
}

\begin{abstract}
Cases of tax evasion in Indonesia have occurred a lot, giving rise to different perceptions on everyone. This study aims to determine the effect of love of money, machiavellian, and equity sensitivity on tax evasion ethics of taxpayers. The population of this research is individual taxpayers who are obliged to tax return and are registered in KPP Pratama in Jakarta, Bogor, Tangerang and Bekasi (Jabotabek) areas. The sample was collected by snowball sampling method. The data used in this study are primary data by using questionnaire with 100 respondents as individual taxpayers. Data analysis was performed using Microsoft Excel 2013 and SmartPLS 3.0. The results of this study showed that (1) love of money has an effect on ethics of tax evasion. (2) machiavellian has no effect on ethics of tax evasion. (3) equity sensitivity has no effect on the ethics of tax evasion. Recomendation for further researchers to be able to add independent variables such as cultural factors, intelligence levels and expand population areas to produce better research.
\end{abstract}

Keywords: Love of Money, Machiavellian, Equity Sensitivity, Tax Evasion Ethics

\section{PERSEPSI WAJIB PAJAK TERKAIT LOVE OF MONEY, MACHIAVELLIAN, DAN EQUITY SENSITIVITY PADA ETIKA PENGGELAPAN PAJAK}

\begin{abstract}
ABSTRAK
Kasus penggelapan pajak di Indonesia sudah banyak terjadi, sehingga menimbulkan persepsi yang berbeda pada setiap orang. Penelitian ini bertujuan untuk menguji peran love of money, machiavellian, dan equity sensitivity pada etika penggelapan pajak wajib pajak. Populasi penelitian ini adalah wajib pajak orang pribadi yang wajib SPT dan terdaftar di KPP Pratama wilayah Jakarta, Bogor, Tangerang, dan Bekasi (Jabotabek). Metode pengumpulan sampel dilakukan dengan metode snowball sampling. Data yang digunakan pada penelitian ini adalah data primer berupa kuesioner dengan responden sebanyak 100 wajib pajak. Analisis data dilakukan dengan bantuan Microsoft Excel 2013 dan SmartPLS 3.0. Hasil penelitian ini menunjukkan bahwa (1) love of money memiliki pengaruh pada etika penggelapan pajak. (2) machiavellian tidak memiliki pengaruh pada etika penggelapan pajak. (3) equity sensitivity tidak memiliki pengaruh pada etika penggelapan pajak. Saran bagi peneliti selanjutnya agar dapat menambah variabel independen seperti faktor budaya, tingkat kecerdasan serta memperluas wilayah populasi untuk menghasilkan penelitian yang lebih baik.
\end{abstract}

Kata-kata Kunci: Love of Money, Machiavellian, Equity Sensitivity, Etika Penggelapan Pajak

Korespondensi: Esther Dwitia. Universitas Pembangunan Nasional Veteran Jakarta, Jalan Fatmawati No. 1, Jakarta Selatan. 12450. Email: dwitia.esther@yahoo.com. 
Jurnal Akuntansi \& Perpajakan, Volume 2, No. 1, Juli 2020

\section{PENDAHULUAN}

Berbagai program pembangunan nasional kini telah dilakukan pemerintah demi memajukan kesejahteraan masyarakat Indonesia, maka diperlukan adanya anggaran pengeluaran dan penerimaan setiap tahunnya yang sering disebut Anggaran Pendapatan dan Belanja Negara (APBN). Pendapatan negara ini dapat bersumber dari berbagai sektor, yaitu sektor internal maupun eksternal. Cara pemerintah untuk mengurangi ketergantungan terhadap sumber pendapatan eksternal yaitu dengan terus menciptakan berbagai upaya untuk memaksimalkan pendapatan internal negara.

Jumlah wajib pajak di Indonesia mengalami peningkatan setiap tahunnya (News.ddtc.co.id, 2019). Namun, realisasi penerimaan pajak dari tahun 2018 ke tahun 2019 masih juga belum mencapai target dan mengalami penurunan (Nasional.kontan.co.id, 2019). Penurunan ini disebabkan karena tingkat kepatuhan wajib pajak orang pribadi yang masih gagal dalam mencapai target. Berdasarkan data Direktorat Jenderal Pajak (DJP), kepatuhan wajib pajak orang pribadi dibagi menjadi dua kategori, yaitu wajib pajak orang pribadi karyawan dan wajib pajak orang pribadi non-karyawan.
Tingkat kepatuhan wajib pajak orang pribadi karyawan tahun 2019 hanya mencapai $73,2 \%$ setara dengan 10,11 juta WP yang seharusnya 13,81 juta WP. Sedangkan tingkat kepatuhan wajib pajak orang pribadi non-karyawan hanya mencapai $75,31 \%$ atau setara dengan 2,29 juta WP dari 3,04 juta WP. Ketidakpatuhan ini dapat berupa penghindaran dan penggelapan pajak (Putu et al., 2019).

Persepsi etis dalam penggelapan pajak dapat dipengaruhi oleh uang yang memiliki peran penting dalam kehidupan sehari-hari. Seseorang yang memiliki sikap cinta uang (Love of Money) biasanya tidak mau mengeluarkan uang untuk sesuatu yang tidak ada dampaknya untuk dirinya. Ketika seseorang sangat mencintai uang, itu akan membuatnya lalai dan mengabaikan nilai-nilai etika dan moral yang dimilikinya. Sama seperti dalam penelitian yang dilakukan Nikara dan Mimba (2019) yang menyatakan bahwa love of money berpengaruh negatif pada persepsi etis mahasiswa akuntansi. Artinya semakin tinggi sifat love of money mahasiswa akuntansi maka menyebabkan persepsi etis mahasiswa menurun. Namun berbeda dengan penelitian yang dilakukan Dewanta dan Machmuddah (2019) yang menyatakan bahwa Love of Money 
Jurnal Akuntansi \& Perpajakan, Volume 2, No. 1, Juli 2020

berpengaruh signifikan positif terhadap persepsi etis seseorang siswa dalam penggelapan pajak.

Persepsi etis penggelapan pajak juga dapat dipengaruhi oleh sifat machiavellian. Sifat machiavellian merupakan suatu persepsi atau keyakinan seseorang tentang hubungan antar personal. Persepsi ini nantinya akan menimbulkan suatu kepribadian yang berdasar pada sikap dalam berhubungan dengan orang lain. Seseorang dengan sifat machiavellian yang tinggi cenderung memiliki sikap manipulatif, melakukan perilaku yang persuasif dalam mencapai tujuan pribadinya, lebih bersifat agresif, dan lebih suka berbohong (Farhan et al., 2019). Biasanya sifat machiavellian ini berpengaruh negatif dalam tindakan etis seseorang. Hal ini sejalan dengan penelitian Shafer dan Wang (2017) yang menyatakan bahwa machiavellian berpengaruh negatif terhadap persepsi etis wajib pajak. Penelitian Nikara dan Mimba (2019) juga menyatakan bahwa machiavellian berpengaruh negatif pada persepsi etis mahasiswa akuntansi. Seseorang dengan sifat machiavellian tinggi cenderung memiliki persepsi etis yang rendah.

Persepsi etis seseorang juga dapat dipengaruhi oleh prinsip keadilan atau
Equity Sensitivity. Menurut Putu et al. (2019) equity sensitivity adalah seseorang yang berpersepsi tentang keadilan dengan membandingkan input dan outcomes yang diperoleh dari orang lain. Pada penelitian Dewi et al. (2018) menyatakan bahwa equity sensitivity berpengaruh pada perilaku etis auditor BPK Perwakilan Provinsi Bali. Semakin tinggi equity sensitivity yang dimiliki maka semakin tinggi perilaku etis yang dimiliki auditor. Auditor dengan titik keseimbangan antara input dan outcomes cenderung bertindak lebih etis dibanding auditor yang tidak memiliki sifat equity sensitivity terutama dalam memberi opini audit. Namun berbeda dengan penelitian yang dilakukan Lucyanda dan Endro (2012) yang menyatakan bahwa equity sensitivity tidak berpengaruh terhadap perilaku etis mahasiswa akuntansi Universitas Bakrie. Hal ini dikarenakan equity sensitivity merupakan bagian dari karakter individu yang berkembang bersama dengan perkembangan kecerdasan emosional seseorang, sehingga pilihan dalam bertindak baik atau tepat tidak selalu berhubungan langsung dengan rasa keadilan. Alasan peneliti tertarik untuk meneliti terkait etika penggelapan pajak karena hasil dari penelitian terdahulu yang tidak konsisten, dan munculnya variabel- 
Jurnal Akuntansi \& Perpajakan, Volume 2, No. 1, Juli 2020

variabel baru yang mempengaruhi etika penggelapan pajak seperti machiavellian dan equity sensitivity.

Rumusan masalah dalam penelitian ini adalah: (1) apakah wajib pajak memiliki persepsi bahwa Love of Money berperan terhadap etika penggelapan pajak?, (2) apakah wajib pajak memiliki persepsi bahwa Machiavellian berperan terhadap etika penggelapan pajak?, (3) apakah wajib pajak memiliki persepsi bahwa Equity Sensitivity berperan terhadap etika penggelapan pajak?

Adapun tujuan penelitian ini adalah untuk menguji: (1) peran Love of Money terhadap persepsi etika penggelapan pajak wajib pajak, (2) peran Machiavellian terhadap persepsi etika penggelapan pajak wajib pajak, (3) peran Equity Sensitivity terhadap persepsi etika penggelapan pajak wajib pajak.

\section{LITERATUR}

Teori perilaku terencana atau yang sering disebut Theory of Planned Behaviour yang dijelaskan Ajzen (dalam Lucyanda \& Endro, 2012) adalah jenis teori yang menjelaskan niat perilaku seseorang dan menjelaskan perilaku orang tersebut. Teori Perilaku Terencana terbentuk dari faktorfaktor penentu yaitu sikap (Attitudes towards the behavior), norma subjektif (subjective norm), persepsi kontrol perilaku (Perceived behavioral control) (Ramdhani, 2016). Attitudes towards the behavior yaitu sikap dari perilaku seseorang didasari oleh keyakinan tentang konsekuensi dari perilaku yang dilakukan tersebut. Subjective norm yaitu persepsi seseorang terhadap harapan dari orang lain mengenai dilakukan dan tidak dilakukannya perilaku tersebut. Perceived behavioral control yaitu persepsi yang dimiliki seseorang tentang sulit atau mudahnya mewujudkan suatu perilaku.

Teori perilaku terencana ini relevan digunakan dalam penelitian ini karena faktor attitudes towards the behavior ini memiliki keterkaitan dengan variabel yang digunakan yaitu love of money, machiavellian, dan equity sensitivity. Seseorang cenderung akan memikirkan konsekuensi positif maupun negarif yang diterima dari melakukan suatu perilaku dalam hal ini terkait penggelapan pajak. Azjen (dalam Ramdhani, 2016) mengatakan bahwa seseorang yang memiliki sikap love of money, machiavellian, serta equity sensitivity biasanya akan menghubungkan perilaku dengan konsekuensi baik manfaat maupun kerugian yang mungkin akan didapatkan apabila melakukan perilaku tersebut (outcome evaluation). 
Jurnal Akuntansi \& Perpajakan, Volume 2, No. 1, Juli 2020

Uang (money) berguna untuk melihat perilaku manusia melalui sikap mereka terhadap uang (Tang \& Chiu, 2008). Sikap ini diwujudkan dalam suatu bentuk rasa cinta terhadap uang atau love of money. Tang (1992) memperkenalkan konsep cinta uang (love of money) sebagai literatur psikologis yang mengukur perasaan subjektif seseorang terhadap uang. Love of money juga diartikan sebagai level kecintaan seseorang terhadap uang yang nantinya akan berpengaruh terhadap persepsi etisnya (Farhan et al., 2019).

Love of money dapat diklasifikasikan menjadi beberapa kelompok berdasarksn tingkat love of money yang dimilikinya, yaitu money worshippers, moneyrepellants dan careless money-admirers. Money worshippers adalah seseorang yang memiliki tingkat keterlibatan terhadap pekerjaan yang tinggi, Money-repellants adalah seseorang yang memiliki tingkat kompetisi yang rendah dan tingkat kesuksesan yang rendah, sedangkan careless money-admirers adalah seseorang yang memiliki tingkat keterlibatan terhadap pekerjaan yang tinggi dan tingkat kesuksesan yang tinggi. Uang bukanlah merupakan segalanya walaupun uang dapat digunakan secara universal (Tang, 1992). Arti uang itu sendiri tergantung pada pandangan dan penggunaannya sesuai kehidupan (Tang, 2008). Jadi dapat disimpulkan love of money adalah sifat yang dimiliki oleh seseorang yang melihat pandangan seseorang tentang pentingnya uang dalam hidupnya.

Istilah Machiavellian pertama kali dikenalkan oleh seorang filsuf, diplomat dan politikus terkenal dari Italia bernama Niccolo Machiavelli. Umumnya Machiavellian berkaitan dengan individu yang manipulatif, menggunakan perilaku persuasif untuk mencapai tujuan pribadinya, dan cenderung agresif (Shafer \& Simmon, 2008). Richmond (2001) mendefinisikan Machiavellian sebagai suatu proses dimana manipulator mendapat imbalan lebih ketika memanipulasi, sementara orang lain mendapatkan kurang tanpa melakukan manipulasi, setidaknya dalam konteks langsung.

Equity sensitivity didefinisikan sebagai suatu persepsi seseorang terhadap keadilan dengan membandingkan antara inputs dan outcomes yang diperoleh dari orang lain (Ustadi \& Utami, 2005). Mudrack (dalam Lucyanda \& Endro, 2012) memberi saran untuk memakai faktor equity sensitivity sebagai salah satu faktor yang dimiliki individu dan mempengaruhi perilaku etis seseorang. Mowday (dalam Lucyanda \& Endro, 2012) menyatakan bahwa teori keadilan sebagai suatu teori 
Jurnal Akuntansi \& Perpajakan, Volume 2, No. 1, Juli 2020

universal dari motivasi seseorang dan sikap harus dapat mengukur perbedaan perilaku seseorang ditempat kerja. Huseman et al. (1987) menerangkan bahwa orang akan memiliki persepsi sendiri tentang adil (equity) dan tidak adil (inequity). Lebih jauh, Husemen membagi persepsi individu terhadap equity dan inequity kedalam tiga kategori, yaitu: benevolents, equity sensitivities, dan entitleds. Individu dengan karakter benevolent cenderung berkepribadian murah hati dan lebih senang memberi daripada menerima (inputs > outcomes). Benevolents juga cenderung melakukan tindakan etis karena memiliki sifat yang tidak mementingkan diri sendiri. Individu equity sensitivities digambarkan sebagai individu yang memiliki keseimbangan antara inputs dan outcomes. Sedangkan individu entitled digambarkan sebagai individu yang lebih senang menerima lebih daripada memberi (outcomes > inputs). Individu entitled lebih banyak menuntut haknya daripada memikirkan apa yang dapat diberikan, sehingga individu ini cenderung melakukan tindakan tidak etis bila hasil yang diperoleh lebih kecil dari input yang diberikan.

Etika memiliki berbagai makna yang berbeda-beda. Salah satu maknanya menurut Dharma et al. (2016) adalah prinsip tingkah laku yang mengatur individu atau kelompok. Misalnya pada penggunaan kata etika personal, yaitu mengacu pada beberapa aturan dalam suatu ruang lingkup dimana setiap orang menjalani kehidupan pribadinya. Selain itu, kita menggunakan istilah akuntansi ketika mengacu pada seperangkat aturan yang mengatur tindakan professional akuntan. Etika juga memiliki makna lain yaitu "kajian moralitas". Hal ini memiliki arti bahwa etika berkaitan dengan moralitas. Meskipun berkaitan, etika tidak sama persis dengan moralitas. Bedanya etika adalah semacam penelaahan (baik aktivitas penelaahan maupun hasil dari penelaahan itu sendiri), sedangkan moralitas merupakan pedoman yang dimiliki individu atau kelompok mengenai apa itu benar dan salah, atau baik dan jahat (Suminarsasi \& Supriyadi, 2011). Penggelapan pajak didefinisikan oleh Mardiasmo (dalam Budiarto et al., 2017) sebagai usaha wajib pajak untuk mengurangi beban pajak dengan cara yang tidak sesuai undangundang. Jadi berdasarkan definisi di atas, dapat disimpulkan etika penggelapan pajak adalah seperangkat aturan yang mengatur seseorang dalam hal ini wajib pajak dalam bertindak terutama dalam melakukan kewajiban pajak agar tidak terjadi penghindaran pajak yang melanggar undang-undang. 
Jurnal Akuntansi \& Perpajakan, Volume 2, No. 1, Juli 2020

Berdasarkan latar belakang dan kajian teori maka kerangka berpikir dalam penelitian ini dapat digambar sebagai berikut:

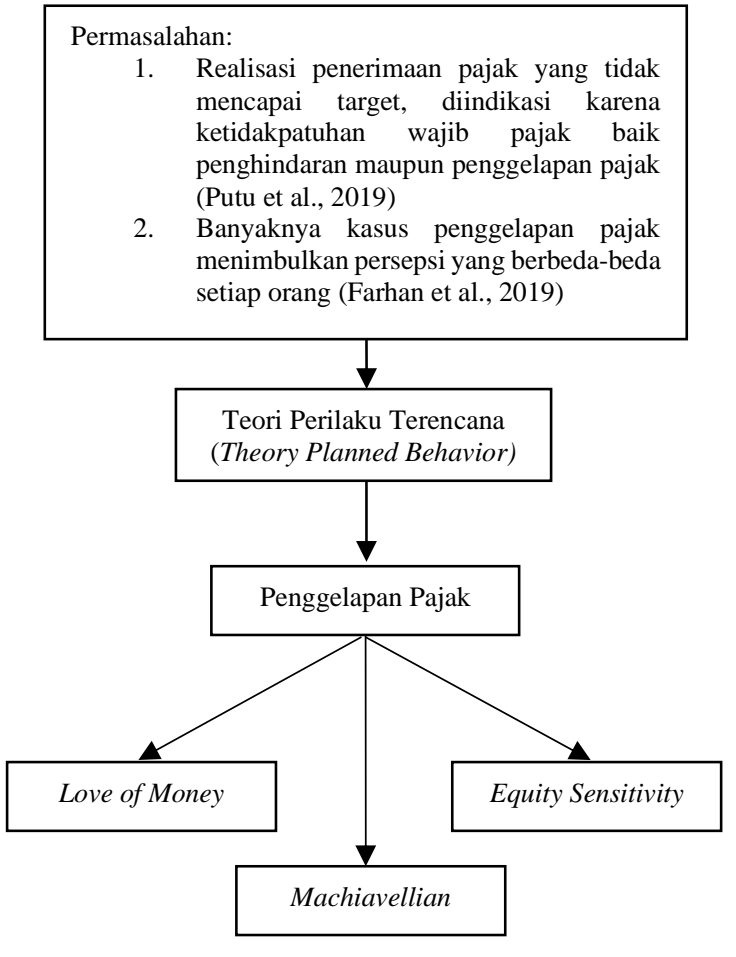

Gambar 1. Kerangka Pemikiran

\section{METODE}

Penelitian ini merupakan penelitian kuantitatif. Penelitian ini menggunakan data primer yang berupa kuesioner. Populasi dalam penelitian ini adalah wajib pajak orang pribadi yang wajib SPT dan terdaftar di KPP Pratama wilayah Jakarta, Bogor, Tangerang dan Bekasi (Jabotabek). Metode pengambilan sampel dalam penelitian ini menggunakan snowball sampling yang berarti teknik pengambilan sampel berdasarkan wawancara atau korespondensi. Metode ini meminta informasi dari sampel pertama untuk mendapat sampel berikutnya, demikian secara terus menerus hingga seluruh kebutuhan sampel penelitian dapat terpenuhi. Kuesioner yang telah disiapkan kemudian didistribusikan secara online dengan bantuan google form.

Pengukuran yang digunakan untuk variabel etika penggelapan pajak menggunakan 4 indikator yang dikembangkan oleh Suminarsasi dan Supriyadi (2011) dan Paramita dan Budiasih (2016). Untuk variabel love of money menggunakan 6 indikator yang dikembangkan Tang (1992) dengan 12 pertanyaan. Variabel machiavellian diukur dengan skala Mach $I V$ sebanyak 6 indikator. Sedangkan untuk variabel equity sensitivity menggunakan Equity Preference Questionnaire (EPQ) yang dikembangkan oleh Sauley dan Bedeian (2000). Seluruh indikator diukur dengan menggunakan skala likert dengan 5 pilihan jawaban mulai dari sangat tidak setuju diberi skor 1 hingga skor tertinggi 5 dengan pilihan jawaban sangat setuju.

Seluruh data yang telah terkumpul nantinya akan dianalisis dan dilakukan pengujian hipotesis dengan bantuan program computer Microsoft Excel 2016 dan SmartPLS 3.2.9. Metode analisis data dilakukan dengan beberapa uji yaitu uji 
Jurnal Akuntansi \& Perpajakan, Volume 2, No. 1, Juli 2020

model pengukuran (outer model), uji model struktural (inner model), uji statistik deskriptif, dan uji hipotesis.

\section{HASIL DAN PEMBAHASAN}

Data penelitian ini didapatkan dari hasil scoring jawaban responden. Peneliti menyebar 145 kuesioner kepada Wajib Pajak Orang Pribadi yang terdaftar di KPP Pratama wilayah Jabotabek. Terdapat 45 kuesioner yang tidak dapat digunakan karena terdapat responden yang tidak memenuhi kriteria responden yang telah ditetapkan sebelumnya, sehingga terdapat 100 kuesioner yang dapat diolah.

Karakteristik responden dikelompokkan berdasarkan umur, pendidikan terakhir, pekerjaan dan domisili responden. Berikut adalah data statistik mengenai karakteristik responden penelitian:

\section{Tabel 1. Data Karakteristik Responden}

\begin{tabular}{|c|c|c|c|}
\hline Keterangan & Deskripsi & $\begin{array}{l}\text { Jum } \\
\text { lah }\end{array}$ & $\begin{array}{c}\begin{array}{c}\text { Persen } \\
\text { tase }\end{array} \\
\end{array}$ \\
\hline \multirow{4}{*}{$\begin{array}{c}\text { Umur } \\
\text { Responden }\end{array}$} & $\begin{array}{l}\text { Jumlah } \\
\text { Responden }\end{array}$ & 100 & $100 \%$ \\
\hline & 24-30 tahun & 60 & $60 \%$ \\
\hline & $31-40$ tahun & 15 & $15 \%$ \\
\hline & $>40$ tahun & 25 & $25 \%$ \\
\hline \multirow{4}{*}{$\begin{array}{c}\text { Pendidikan } \\
\text { Terakhir }\end{array}$} & $\begin{array}{l}\text { Jumlah } \\
\text { Responden }\end{array}$ & 100 & $100 \%$ \\
\hline & SMP & 1 & $1 \%$ \\
\hline & SMA & 23 & $23 \%$ \\
\hline & $\begin{array}{l}\text { Diplomat / } \\
\text { sederajat }\end{array}$ & 15 & $15 \%$ \\
\hline
\end{tabular}

\begin{tabular}{|c|c|c|c|}
\hline & $\begin{array}{l}\text { Sarjana / } \\
\text { sederajat }\end{array}$ & 61 & $61 \%$ \\
\hline \multirow{7}{*}{$\begin{array}{l}\text { Pekerjaan } \\
\text { Responden }\end{array}$} & Jumlah & & \\
\hline & Responden & 100 & $100 \%$ \\
\hline & Pegawai & & \\
\hline & Negeri & 8 & $8 \%$ \\
\hline & Pegawai & & \\
\hline & Swasta & 88 & $88 \%$ \\
\hline & Wirausaha & 4 & $4 \%$ \\
\hline \multirow{4}{*}{$\begin{array}{l}\text { Domisili } \\
\text { Responden }\end{array}$} & Jumlah & & \\
\hline & Responden & 100 & $100 \%$ \\
\hline & Jakarta & 27 & $27 \%$ \\
\hline & Bogor & 13 & $13 \%$ \\
\hline
\end{tabular}

\begin{tabular}{|c|c|c|}
\hline Tangerang & 10 & $10 \%$ \\
\hline Bekasi & 50 & $50 \%$ \\
\hline
\end{tabular}

Sumber: Hasil Penelitian (2020)

Berdasarkan tabel 1 dapat dilihat bahwa berdasarkan umur responden yang paling banyak mengisi kuesioner adalah responden yang berusia antara 24 hingga 30 tahun. Kemudian dari segi pendidikan terakhir responden terbanyak berpendidikan terakhir sarjana/sederajat yaitu sebanyak 61 responden. Berdasarkan pekerjaan responden, mayoritas responden bekerja sebagai pegawai swasta sebanyak 88 responden. Serta berdasarkan domisili, sebanyak 50 responden berdomisili di Bekasi.

Uji model pengukuran atau outer model digunakan untuk melihat hubungan variabel laten dengan indikatorindikatornya. Uji validitas konvergen digunakan untuk melihat hubungan antara skor item indikator dengan variabel latennya. Item pertanyaan dinyatakan valid 
Jurnal Akuntansi \& Perpajakan, Volume 2, No. 1, Juli 2020

apabila memiliki nilai outer loading lebih besar dari 0,6. Berikut merupakan hasil uji validitas konvergen setelah mengeluarkan indikator-indikator yang memiliki outer loading di bawah 0,6:

Tabel 2. Nilai Outer Loading (Model Pengukuran)

\begin{tabular}{|c|c|c|}
\hline Indikator & $\begin{array}{c}\text { Nilai Outer } \\
\text { Loading }\end{array}$ & $\begin{array}{c}\text { Keteranga } \\
\mathbf{n} \\
\end{array}$ \\
\hline \multicolumn{3}{|c|}{ Love of Money (X1) } \\
\hline LOM 2 & 0.748 & Valid \\
\hline LOM 5 & 0.619 & Valid \\
\hline LOM 6 & 0.751 & Valid \\
\hline LOM 7 & 0.757 & Valid \\
\hline LOM 8 & 0.748 & Valid \\
\hline LOM 11 & 0.688 & Valid \\
\hline LOM 12 & 0.730 & Valid \\
\hline \multicolumn{3}{|c|}{ Machiavellian (X2) } \\
\hline MACH 1 & 0.703 & Valid \\
\hline MACH 3 & 0.829 & Valid \\
\hline MACH 5 & 0.692 & Valid \\
\hline MACH 7 & 0.627 & Valid \\
\hline $\begin{array}{l}\text { MACH } \\
10 \\
\end{array}$ & 0.677 & Valid \\
\hline \multicolumn{3}{|c|}{ Equity Sensitivity (X3) } \\
\hline ES 4 & 0.693 & Valid \\
\hline ES 5 & 0.983 & Valid \\
\hline ES 6 & 0.634 & Valid \\
\hline \multicolumn{3}{|c|}{ Etika Penggelapan Pajak (Y) } \\
\hline EPP 1 & 0.869 & Valid \\
\hline EPP 2 & 0.892 & Valid \\
\hline EPP 3 & 0.859 & Valid \\
\hline EPP 5 & 0.676 & Valid \\
\hline
\end{tabular}

Sumber: Hasil Penelitian (2020)

Berdasarkan tabel 2 dapat dilihat bahwa semua nilai outer loading pada setiap indikator memiliki nilai lebih besar dari 0.6 sehingga semua indikator variabel sudah memiliki validitas konvergen yang baik dan tidak perlu dieliminasi atau dikeluarkan dari model.

Uji validitas diskriminan bertujuan untuk melihat setiap konsep pada setiap variabel memiliki perbedaan dengan variabel lainnya. Nilai loading pada setiap indikator dalam suatu variabel laten memiliki nilai loading paling besar disbanding dengan nilai loading pada variabel laten lainnya. Berikut merupakan hasil uji validitas diskriminan:

Tabel 3. Nilai Validitas Diskriminan Berdasarkan cross-loading

\begin{tabular}{|c|c|c|c|c|}
\hline & EPP & ES & LOM & МАСН \\
\hline EPP 1 & 0.869 & -0.213 & 0.387 & 0.214 \\
\hline EPP 2 & 0.892 & -0.195 & 0.285 & 0.249 \\
\hline EPP 3 & 0.859 & -0.154 & 0.405 & 0.127 \\
\hline EPP 5 & 0.676 & -0.012 & 0.233 & 0.282 \\
\hline ES 4 & -0.051 & 0.693 & -0.101 & 0.041 \\
\hline ES 5 & -0.212 & 0.983 & -0.051 & -0.042 \\
\hline ES 6 & -0.025 & 0.634 & 0.083 & 0.040 \\
\hline LOM 2 & 0.317 & 0.027 & 0.748 & 0.049 \\
\hline LOM 5 & 0.187 & 0.111 & 0.619 & 0.190 \\
\hline LOM 6 & 0.320 & -0.016 & 0.751 & 0.185 \\
\hline LOM 7 & 0.323 & -0.101 & 0.757 & 0.122 \\
\hline LOM 8 & 0.229 & 0.074 & 0.748 & 0.055 \\
\hline LOM 11 & 0.292 & -0.203 & 0.689 & 0.129 \\
\hline LOM 12 & 0.321 & -0.081 & 0.730 & 0.245 \\
\hline МАСН 1 & 0.148 & -0.168 & 0.109 & 0.703 \\
\hline МАСН 3 & 0.182 & 0.002 & 0.205 & 0.829 \\
\hline МАСН 5 & 0.068 & 0.053 & 0.169 & 0.692 \\
\hline МАСН 7 & 0.132 & 0.007 & -0.003 & 0.627 \\
\hline МАСН 10 & 0.254 & 0.030 & 0.169 & 0.677 \\
\hline
\end{tabular}
dilihat bahwa nilai loading pada setiap item 
Jurnal Akuntansi \& Perpajakan, Volume 2, No. 1, Juli 2020

indikator lebih besar dari nilai crossloading nya. Sehingga dapat disimpulkan bahwa semua variabel laten sudah memiliki validitas diskriminan yang baik.

Uji reliabilitas dilihat berdasarkan nilai composite reliability dan cronbach's alpha nya. Apabila suatu konstruk memiliki reliabilitas yang baik apabila memiliki nilai composite reliability lebih besar atau sama dengan 0,7 dan nilai cronbach's alpha lebih besar atau sama dengan 0,7 (Ghozali, 2008). Tabel 4 memperlihatkan hasil uji reliabilitas.

Tabel 4. Nilai Composite Reliability dan Cronbach's Alpha

\begin{tabular}{lccc}
\hline Variabel & $\begin{array}{c}\text { Composite } \\
\text { Reliability }\end{array}$ & $\begin{array}{c}\text { Cronbac } \\
\boldsymbol{h} \text { 's } \\
\text { Alpha }\end{array}$ & $\begin{array}{c}\text { Keter } \\
\text { angan }\end{array}$ \\
\hline $\begin{array}{l}\text { Etika } \\
\text { Penggelapan } \\
\text { Pajak }\end{array}$ & 0.896 & 0.845 & $\begin{array}{c}\text { Reliab } \\
\text { el }\end{array}$ \\
\hline $\begin{array}{l}\text { Love of } \\
\text { Money }\end{array}$ & 0.883 & 0.847 & $\begin{array}{c}\text { Reliab } \\
\text { el }\end{array}$ \\
\hline $\begin{array}{l}\text { Machiavelli } \\
\text { an }\end{array}$ & 0.834 & 0.772 & $\begin{array}{c}\text { Reliab } \\
\text { el }\end{array}$ \\
\hline $\begin{array}{l}\text { Equity } \\
\text { Sensitivity }\end{array}$ & 0.822 & 0.750 & $\begin{array}{c}\text { Reliab } \\
\text { el }\end{array}$ \\
\hline
\end{tabular}

Sumber: Hasil Penelitian (2020)

Berdasarkan tabel 4 dapat dilihat bahwa setiap konstruk memiliki reliabilitas yang baik. Hal ini karena nilai composite reliability dan cronbach's alpha pada setiap variabel memiliki nilai lebih dari 0.7 .

Selanjutnya adalah uji model struktural atau yang sering disebut dengan inner model. Uji model struktural digunakan untuk memperlihatkan hubungan antar variabel laten. Model struktural dapat dilihat dengan menggunakan nilai $\mathrm{R}^{2}$ untuk variabel dependen dan koefisien jalur melalui nilai original sample.

Tabel 5. Hasil Uji $\mathbf{R}^{2}$

\begin{tabular}{lcc}
\hline Variabel & $\begin{array}{c}\text { R- } \\
\text { Square }\end{array}$ & $\begin{array}{c}\text { Adjuste } \\
\text { d R- } \\
\text { Square }\end{array}$ \\
\hline $\begin{array}{l}\text { Etika Penggelapan } \\
\text { Pajak }\end{array}$ & 0.221 & 0.197 \\
\hline
\end{tabular}

Sumber: Hasil Penelitian (2020)

Tabel 5 menunjukkan nilai adjusted r-square sebesar 0.197. Hal ini berarti variabel etika penggelapan pajak diprediksikan dalam variabel independen yaitu love of money, machiavellian dan equity sensitivity sebesar $19.7 \%$ sedangkan sisanya $80.3 \%$ dijelaskan oleh variabel lain yang tidak diteliti dalam penelitian ini.

Selanjutnya, melihat koefisien jalur atau path coefficient. koefisien jalur digunakan untuk melihat arah hubungan antara variabel independen dengan variabel dependennya. Berikut adalah hasil nilai original sample pada boothstrapping SamrtPLS:

Tabel 6. Hasil Boothstrapping Nilai Original Sample 
Jurnal Akuntansi \& Perpajakan, Volume 2, No. 1, Juli 2020

Love of money $\rightarrow$ Etika

Penggelapan Pajak

Machiavellian $\rightarrow$ Etika

Penggelapan Pajak

Equity Sensitivity $\rightarrow$

Etika Penggelapan

Pajak

Sumber: Hasil Penelitian (2020)

Dari tabel di atas dapat dilihat bahwa hubungan antara love of money dengan etika penggelapan pajak memiliki arah hubungan yang positif yaitu sebesar 0.338 . Selanjutnya machiavellian dengan etika penggelapan pajak juga memiliki arah hubungan yang positif. Sedangkan pada equity sensitivity dengan etika penggelapan pajak memiliki arah hubungan yang negatif artinya equity sensitivity memiliki kekuatan hubungan yang kecil.

Analisis statistik deskriptif ini dilakukan untuk menganalisis data yang bersumber pada hasil dari jawaban responden terhadap setiap indikator variabel. Uji statistik deskriptif dilihat berdasarkan nilai mean (rata-rata), median, dan modus. Beberapa indikator variabel dalam penelitian ini tidak dapat digunakan dalam pengujian. Analisis statistik deskriptif disajikan pada tabel 7 sebagai berikut:

\section{Tabel 7. Statistik Deskriptif}

\begin{tabular}{|c|c|c|c|c|}
\hline Variabel & $\mathbf{N}$ & $\begin{array}{c}\text { Me } \\
\text { an }\end{array}$ & $\begin{array}{c}\text { Medi } \\
\text { an }\end{array}$ & $\begin{array}{c}\text { Mod } \\
\text { us }\end{array}$ \\
\hline & 10 & 22.3 & & \\
\hline \multirow[t]{2}{*}{ Love of Money } & 0 & 9 & 22 & 23 \\
\hline & 10 & 18.3 & & \\
\hline \multirow[t]{2}{*}{ Machiavellian } & 0 & 0 & 19 & 21 \\
\hline & 10 & 10.5 & & \\
\hline Equity Sensitivity & 0 & 0 & 11 & 11 \\
\hline Etika Penggelapan & 10 & & & \\
\hline Pajak & 0 & 9.68 & 9 & 8 \\
\hline
\end{tabular}

Sumber: Hasil Penelitian (2020)

Uji hipotesis dapat dilihat dari hasil boothstrapping pada tabel $t$-statistic untuk melihat apakah terdapat pengaruh variabel independen pada variabel dependen dengan tingkat signifikansi 5\%. Pengujikan hipotesis ini dilakukan dengan melihat nilai $t$-statistic dan $p$-value. Jika nilai $t$-statistic lebih besar dari t-tabel yaitu sebesar 1.96 maka variabel independen tersebut memiliki pengaruh terhadap variabel dependennya. Selanjutnya jika nilai $p$-value lebih kecil dari 0.05 maka dinyatakan bahwa terdapat pengaruh yang signifikan antara variabel independen dengan variabel dependen. Berikut disajikan besar nilai $t$ statistic dan nilai p-value pada tabel di bawah ini:

Tabel 8. Hasil Uji Hipotesis

\begin{tabular}{lcc}
\hline & t-statistic & p-value \\
\hline $\begin{array}{l}\text { Love of money } \rightarrow \\
\text { Etika Penggelapan } \\
\text { Pajak }\end{array}$ & 4.154 & 0.000 \\
\hline
\end{tabular}


Jurnal Akuntansi \& Perpajakan, Volume 2, No. 1, Juli 2020

Machiavellian $\rightarrow$

Etika Penggelapan

Pajak

Equity Sensitivity $\rightarrow$

Etika Penggelapan

Pajak

Sumber: Hasil Penelitian (2020)

Berdasarkan tabel 8 di atas, dapat dilihat variabel love of money memiliki nilai $t$-statistic lebih besar dari t-tabel (4.154>1.96) dan nilai $p$-value yang lebih kecil dari $0.05 \quad(0.000<0.05)$. Hal ini menunjukkan bahwa variabel love of money memiliki pengaruh yang signifikan terhadap variabel etika penggelapan pajak. Hal ini tidak terjadi pada variabel machiavellian, karena nilai t-statistic variabel machiavellian sebesar 1.724 yang mana nilai $t$-statistic lebih kecil dari 1.96 dengan nilai p-value sebesar 0.085 . Sehingga dapat disimpulkan bahwa variabel machiavellian tidak memiliki pengaruh terhadap variabel etika penggelapan pajak. Selanjutnya pada variabel equity sensitivity memiliki nilai $t$ statistic sebesar 1.089 dimana nilai ini lebih besar dari nilai t-tabel $(1.089<1.96)$ dengan nilai $p$-value yang lebih besar dari 0.05 yaitu sebesar 0.277 . Hal ini memiliki arti bahwa variabel equity sensitivity tidak memiliki pengaruh yang signifikan terhadap variabel etika penggelapan pajak.
Berdasarkan hasil uji hipotesis variabel love of money pada etika penggelapan pajak, dapat disimpulkan bahwa $\mathrm{H} 1$ dalam penelitian ini diterima. Dengan kata lain love of money memiliki pengaruh yang signifikan terhadap etika penggelapan pajak.

Arah koefisien menunjukkan hubungan yang positif artinya wajib pajak yang memiliki sifat love of money yang tinggi akan cenderung memiliki persepsi etis yang lebih baik sehingga tidak akan melakukan penggelapan pajak. Semakin tinggi tingkat love of money yang dimiliki wajib pajak, maka semakin tinggi juga tingkat persepsi etisnya. Tingkat love of money tidak mengurangi persepsi etis yang dimiliki wajib pajak dikarenakan wajib pajak yang menjadi responden sebagian besar berlatar belakang pendidikan diploma maupun sarjana, yang mana mereka memahami atau mengerti betul pentingnya nilai uang dalam kehidupannya. Sehingga semakin tinggi tingkat love of money semakin etis tindakan yang akan dilakukan dalam hal ini tidak melakukan penggelapan pajak.

Hasil uji hipotesis variabel machiavellian pada etika penggelapan pajak menunjukkan bahwa sifat machiavellian ternyata tidak memiliki 
Jurnal Akuntansi \& Perpajakan, Volume 2, No. 1, Juli 2020

pengaruh pada etika penggelapan pajak. Artinya $\mathrm{H} 2$ dalam penelitian ini ditolak.

Berdasarkan penelitian ini wajib pajak ternyata memiliki tingkat sifat machiavellian yang sedang. Hal ini dapat terjadi karena tingkat pengetahuan wajib pajak sudah sangat memadai dengan konsekuensi yang akan didapat apabila melakukan manipulasi saat ingin melakukan penggelapan pajak. Misalnya pada saat pemeriksaan pajak oleh fiskus adalah salah satu faktor yang membuat seseorang yang memiliki sifat machiavellian tidak melakukan penggelapan pajak karena akan jauh lebih merugikan jika ketahuan melakukannya. Hal ini sejalan dengan teori perilaku terencana pada faktor attitudes towards the behavior yaitu sikap seseorang yang didasari oleh keyakinan mengenai konsekuensi dari perilaku yang dilakukan tersebut. Berdasarkan penjelasan tersebut, maka disimpulkan bahwa machiavellian tidak memiliki pengaruh pada etika penggelapan pajak.

Berdasarkan hasil uji hipotesis sebelumnya, maka dapat disimpulkan bahwa H3 dalam penelitian ini ditolak. Dengan kata lain variabel equity sensitivity tidak memiliki pengaruh pada etika penggelapan pajak.
Pada penelitian ini, equity sensitivity menunjukkan bahwa tidak adanya pengaruh pada persepsi etika penggelapan pajak. Hal ini terjadi karena berdasarkan hasil uji statistik deskriptif rata-rata responden menjawab netral pada pernyataan yang terdapat pada kuesioner. Hal ini menunjukkan bahwa wajib pajak tidak tergoda untuk melakukan suatu tindakan yang tidak etis dalam hal ini penggelapan pajak berdasarkan tingkat keadilan (equity sensitivity) yang mereka terima, karena tingkat keadilan tersebut bersifat relatif artinya berbeda-beda makna nya pada setiap orang. Suatu tindakan dirasa adil menurut seseorang belum tentu dirasa adil juga menurut orang lain begitupula sebaliknya. Sehingga equity sensitivity tidak memiliki pengaruh pada persepsi etika penggelapan pajak.

\section{KESIMPULAN}

Penelitian ini memiliki tujuan untuk menguji peran love of money, machiavellian, equity sensitivity pada persepsi etika penggelapan pajak wajib pajak. Berdasarkan hasil analisis yang telah dilakukan, maka dapat ditarik kesimpulan bahwa love of money memiliki pengaruh pada etika penggelapan pajak. Sedangkan machiavellian dan equity sensitivity tidak 
Jurnal Akuntansi \& Perpajakan, Volume 2, No. 1, Juli 2020

memiliki pengaruh pada etika penggelapan pajak.

Saran bagi peneliti selanjutnya diharapkan dapat menambah variabel independen lain seperti budaya dan tingkat kecerdasan, serta dapat melihat karakteristik responden berdasarkan besar penghasilan responden. Karena variabel yang dipakai adalah love of money, sehingga besar penghasilan dirasa memiliki hubungan yang cukup erat pada persepsi etis seseorang.

\section{REFERENSI}

Budiarto, D. S., Nurmalisa, F., \& Yennisa. (2017). Hubungan Antara Religiusitas Dan Machiavellian Dengan Tax Evasion: Riset Berdasarkan Perspektif Gender. Telaah Bisnis, 17(2), 145168.

http://journal.stimykpn.ac.id/index.ph $\mathrm{p} / \mathrm{tb} /$ article/view/54/42

Dewanta, M. A., \& Machmuddah, Z. (2019). Gender, Religiosity, Love of Money, and Ethical Perception of Tax Evasion. Jurnal Dinamika Akuntansi Dan Bisnis, 6(1), 71-84. https://doi.org/10.24815/jdab.v6i1.10 990

Dewi, I. G. P. E. R. (2019). Filosofi Tri Kaya Parisudha Memoderasi Pengaruh Equity Sensitivity dan
Ethical Sensitivity Pada Perilaku Etis Auditor Badan Pemeriksa Keuangan Perwakilan Provinsi Bali. E-Jurnal Institut Hindu Dharma Negeri, 5 No 1, 43-56.

http://ejournal.ihdn.ac.id/index.php/J

PM

Dharma, L., Agusti, R., \& Kurnia, P. (2016). Pengaruh Gender, Pemahaman Perpajakan dan Religiusitas terhadap Persepsi Penggelapan Pajak. Jurnal Online Mahasiswa Fakultas Ekonomi Universitas Riau, 3(1), 1565-1578.

Farhan, M., Helmy, H., \& Afriyenti, M. (2019). Pengaruh machiavellian dan love of money terhadap persepsi etika penggelapan pajak dengan religiusitas sebagai variabel moderasi. Jurnal Eksplorasi Akuntansi, 1(1), 470-486.

Ghozali, I. (2008). Structural equation modeling: Metode Alternatif Dengan Partial Least Square (PLS). Badan Penerbit Universitas Diponegoro.

Huseman, R. C., Hatfield, J. D., \& Miles, E. W. (1987), on Equity Theory: The Equity Sensitivity Construct. 12(2), 222-234.

https://doi.org/10.5465/amr.1987.430 7799

Lucyanda, J., \& Endro, G. (2012). FaktorFaktor yang Mempengaruhi Perilaku 
Jurnal Akuntansi \& Perpajakan, Volume 2, No. 1, Juli 2020

Etis Mahasiswa Akuntansi Universitas

Bakrie. Media Riset Akuntansi. Vol. 02 No. 02.

Nikara, I. A. G. I. K., \& Mimba, N. P. S. H. (2019). Pengaruh Love of Money , Machiavellian , Idealisme dan

Religiusitas pada Persepsi Etis Mahasiswa Akuntansi. E-Jurnal Akuntansi Universitas Udayana, 26, 536-562.

https://doi.org/https://doi.org/10.2484

3/EJA.2019.v26.i01.p20.

Paramita, M., \& Budiasih, I. (2016).

Pengaruh Sistem Perpajakan,

Keadilan, Dan Teknologi Perpajakan

Pada Persepsi Wajib Pajak Mengenai

Penggelapan Pajak. E-Jurnal

Akuntansi, 17(2), 1030-1056.

Putu, N., Murtining, S., \& Dwiyanti, K. T.

(2019). Pengaruh Love Of Money ,

Machiavellian, dan Equity Sensitivity

Terhadap Persepsi Etika Penggelapan

Pajak ( Tax Evasion ). E-Jurnal

Akuntansi Universitas Udayana, 26, 1412-1435.

Ramdhani, N. (2016). Penyusunan Alat

Pengukur Berbasis Theory of Planned

Behavior. Buletin Psikologi, 19(2), 55-69.

https://doi.org/10.22146/bpsi.11557.

Richmond, K. A. (2001). Ethical reasoning,

Machiavellian behavior, and gender:
The impact on accounting students' ethical decision making. ProQuest Dissertations.

https://doi.org/10.1017/CBO9781107 415324.004.

Sauley, K. S., \& Bedeian, A. G. (2000). Equity sensitivity: Construction of a measure and examination of its psychometric properties. Journal of Management, $\quad$ 26(5), 885-910. https://doi.org/10.1177/01492063000 2600507

Shafer, W. E., \& Wang, Z. (2017). Machiavellianism, social norms, and taxpayer compliance. Business Ethics, October 2016, 1-14. https://doi.org/10.1111/beer.12166.

Suminarsasi, W., \& Supriyadi. (2011). Pengaruh Keadilan, Sistem Perpajakan, dan Diskriminasi Terhadap Persepsi Wajib Pajak Mengenai Etika Penggelapan Pajak (Tax Evasion). 1(2 (oktober)).

Tang, T. L. P. (1992a). The Meaning of Money Revisited: The Development of the Money Ethic Scale. Journal of Organizational Behavior, 13(2), 197202. http://eric.ed.gov/?id=ED306494 Tang, T. L. P. (1992b). The Meaning of Money Revisited: The Development of the Money Ethic Scale. Journal of Organizational Behavior, 13(2), 197- 
Jurnal Akuntansi \& Perpajakan, Volume 2, No. 1, Juli 2020

202.

Tang, T. L. P., Chen, Y. J. \& Sutarso, T. (2008). Bad Apples in Bad (Business)

Barells: The Love of Money,

Machiavellian, Risk Tolerance, and

Unethical Behaviour. Management

Decision, 46(2), 243-263.

Ustadi, N. H., \& Utami, R. D. (2005). Analisis Perbedaan Faktor-Faktor

Individual Terhadap Persepsi Perilaku

Etis Mahasiswa. Jurnal Akuntansi \& Auditing. Vol. 01 No. 02, 16 